Article

\title{
An Industrial System Powered by Wind and Coal for Aluminum Production: A Case Study of Technical Demonstration and Economic Feasibility
}

\author{
Yuan-Zhang Sun ${ }^{1}$, Jin Lin ${ }^{2, *}$, Yong-Hua Song ${ }^{2}$, Jian $\mathrm{Xu}^{1}, \mathrm{Xiao}^{-M i n g ~} \mathrm{Li}^{3}$ and \\ Jian-Xun Dong 4
}

1 School of Electrical Engineering, Wuhan University, Wuhan 430072, China;

E-Mails: yzsun@tsinghua.edu.cn (Y.-Z.S.); xujian@whu.edu.cn (J.X.)

2 State Key Laboratory of Power Systems, Department of Electrical Engineering, Tsinghua University, Beijing 100084, China; E-Mail: yhsong@tsinghua.edu.cn

3 China Power Investment Corporation, Beijing 100140, China;

E-Mail: lixiaomin@cpicorp.com.cn

4 CPI Energy Group Meng-Dong Group, Tongliao 028000, Inner Mongolia, China; E-Mail: dongjx63@163.com

* Author to whom correspondence should be addressed; E-Mail: linjin@tsinghua.edu.cn; Tel.: +86-10-62795903-802; Fax: +86-10-62796853-806.

Received: 8 October 2012; in revised form: 31 October 2012 / Accepted: 7 November 2012 / Published: 21 November 2012

\begin{abstract}
This paper presents a case study of an isolated industrial power system for aluminum production. The novel concept is that the cost of aluminum electrolysis can be significantly reduced by innovative application of hybrid systems incorporating wind energy and low-grade coal. In addition, the low-grade coal, which sale is not profitable in the market, can be locally consumed by the isolated power system. The power system thus fully utilizes the local resources in an effective and economic manner. However, several technical and economic issues are still of concern because the industrial system is isolated from the state grid. This paper hence discusses these issues and demonstrates the feasibility of such a hybrid power system from the technical and economic perspectives.
\end{abstract}

Keywords: isolated power system; wind power; aluminum production; technical demonstration; economic feasibility 


\section{Introduction}

The ever-increasing demand for clean energy is stimulating the worldwide installation of wind generators to drive our future society. As one of the largest energy consumers, China has its own plan to install more than $150 \mathrm{GW}$ wind power by year 2020 aiming to reduce fossil energy consumption and $\mathrm{CO}_{2}$ emissions [1]. However, in China, the wind industry cannot follow the same paths of some developed countries, such as Germany and, Denmark. In these countries, the wind resources are relatively close to the load center, so most of wind power can be consumed locally [1-3]. In contrast, the on-shore wind resources in China are mostly concentrated in the developing western provinces, such as Gansu, Xinjiang and Inner Mongolia. The wind power generation is hence quite far away from the load centers located on the eastern coast and there are plenty of technical issues with the transmission of a large amount of wind power over long-distances [4,5]. By the end of 2009, more than half of the installed wind power has not been connected to the grid due to the lagging grid infrastructure [6,7] and the lack of appropriate grid management systems [8,9]. This represents a huge economic waste and impedes the achievement of China's energy emission reduction targets.

To overcome the above problems, one of the solutions is off-grid technology, which enables high penetration of wind power integrated into an isolated system. The technology is quite attractive for the developing wind industry in China. Because an isolated power system does not require support from an external grid, huge investments for the construction of grid transmission systems can be avoided [10]. Some other technical issues caused by long-distance transmission can also be avoided, such as voltage instability [5] and low frequency oscillation [4], so the wind generation can be consumed locally in the western provinces of China in an effective manner. The off-grid technology is not only valuable for China, but also widely discussed in worldwide research. From the technical aspect, some published literature [11] has discussed on this topic. It has been verified to be feasible [11], stable [12], reliable [13] and flexible [14] in theory to integrate high penetration of wind power into diverse isolated systems. From the application aspect, the off-grid technology has also been adopted in some actual power systems. Reference [15] introduces the applications of off-grid technology on the Canary Islands (Spain). In this study, the integration of high percentage of wind power in the Canaries is demonstrated to be practicable based on both cost and risk analysis results. Reference [16] discusses the implementation of an isolated system located in the city of Johor Bahru (Malaysia). Seven different configurations are compared in the study and it is concluded that the hybrid energy system of PV/wind/diesel/battery only requires a reasonable investment to replace the original stand-alone diesel system and reduces the emission of $\mathrm{CO}_{2}$, especially in a high diesel price scenario. A techno-economic assessment is presented in [17,18] for an off-grid hybrid generation system located on the north-eastern part of Saudi Arabia. The assessment result demonstrates that the wind-diesel system becomes economically attractive if the carbon tax is taken into account and if diesel prices keep rising. Study [19] focuses on the electricity supply in the Brazilian Amazon Region. The authors recognize the benefits of isolated systems with wind power integrated in the Amazon Region. The off-grid technology helps to preserve the environment, whilst generating wealth and employment for the region.

In China, the primary industry sector is also the main energy consumer. During the first seven months in 2010, industrial use of electricity was 1.81 trillion $\mathrm{kWh}$. Compared to the same period 
in 2009, it represents an increase of $22.69 \%$, much higher than that of the tertiary industry consumption (15.39\%), and that of household consumption (13.07\%) [20]. Based on the aforementioned literature review, most current off-grid technologies are used for civil applications, the system capacity of which is much lower than that of industry applications. Also, most of the isolated grid is designed based on diesel generators. The start-up, as well as the power ramping rate of diesel generators is faster than that of coal-powered generators, so diesel generators are more capable of compensating wind power fluctuations in an isolated power system [21]. Considering that China is poor in oil but rich in coal [22], a wind-coal powered solution would be more suitable for China to address the wind integration issue.

This paper presents an industry project of an isolated power system located in Inner Mongolian province financed by the China Power Investment Corporation, which is one of the five largest generation corporations of China [23]. Originally, the industry system was powered by coal-fired generators for the electrolysis of aluminum, which has been categorized into the high energy consumption sector of China [24]. Due to the rapidly rising coal prices, the investor plans to integrate more wind power to control the electrolysis costs. However, the integration of wind power raises several technical and economic issues. One major technical issue, discussed in this paper, is the power balancing of this isolated system. Since the power system is distant from the inter-connected state grid, the system will reach a wind penetration level at around $47 \%$, without any external-grid support. The power balancing of this isolated system should be carefully investigated before the construction of such a system at this high wind penetration level. Another issue is the economic aspect. With present technologies, the construction cost of wind farms is almost twice that of conventional generators [25]. The profitability of the hybrid wind-coal power system should be examined before the investment in wind generators. This paper hence discusses this economic issue. The methodology adopted is to study the investment profitability by calculating the economic indicators of "internal rate of return" and "payback period". Through the techno-economical assessment, the isolated system is demonstrated to be both feasible and profitable. The investment will result in higher and cleaner profits from aluminum production using the presented wind-coal technologies.

\section{The Industrial Power System and the Local Resources}

This section gives a background review on the industrial power system and presents the motivation for the construction of additional generation capacity, as well as the integration of wind power.

\subsection{Description of the Current Industry System}

The power system is located in Zhahazhuoer (ZHZE), Tongliao (TL) Region, Inner Mongolian (IMo) province, which is one of China's largest energy producing provinces thanks to its substantial energy resources [26]. This system is constructed for the power supply of an aluminum electrolysis plant, which was financed by the China Power Investment Corporation in 2006. This aluminum production stimulates the local employment and brings considerable tax-revenues for TL's government. Therefore, in 2006 this project was regarded as one of the most important industry projects of IMo province [27]. As of 2010, the aluminum electrolysis load was around $992 \mathrm{MW}$, and total generation capacity around $1200 \mathrm{MW}$, as shown in Table 1. 
Table 1. The load and generator profiles.

\begin{tabular}{|c|c|c|c|c|}
\hline $\begin{array}{c}\text { Load } \\
\text { Number }\end{array}$ & $\begin{array}{c}\text { Load } \\
\text { Capacity( MW) }\end{array}$ & Usage & $\begin{array}{l}\text { Generator } \\
\text { Number }\end{array}$ & $\begin{array}{c}\text { Generator } \\
\text { Capacity (MW) }\end{array}$ \\
\hline HJL\#1 & 350 & $\begin{array}{l}\text { Aluminum } \\
\text { Electrolysis }\end{array}$ & HJ\#1 & 50 \\
\hline HJL\#2 & 440 & $\begin{array}{l}\text { Aluminum } \\
\text { Electrolysis }\end{array}$ & $\mathrm{HJ} \# 2$ & 50 \\
\hline HJLH\#1 \#3 & 100 & Heat & HJ\#3 & 100 \\
\hline \multirow[t]{5}{*}{ HJG\#1 \#8 } & 102 & Auxiliary Power & HJ\#4 & 100 \\
\hline & & & HJ\#5 & 150 \\
\hline & & & HJ\#6 & 150 \\
\hline & & & HJ\#7 & 300 \\
\hline & & & $\mathrm{HJ} \# 8$ & 300 \\
\hline $\begin{array}{l}\text { Load in Total } \\
\text { (MW) }\end{array}$ & 992 & & $\begin{array}{l}\text { Generation in } \\
\text { Total (MW) }\end{array}$ & 1200 \\
\hline
\end{tabular}

From Table 1, the installed generation capacity is currently enough to satisfy the consumption of aluminum electrolysis and its auxiliary facilities in 2010. However, being one of the most important construction materials, aluminum consumption in China keeps increasing rapidly with the economic bloom. The China Power Investment Corporation hence plans to expand the aluminum production in order to satisfy this ever-growing market. According to the investment blueprint, another aluminum electrolysis plant has been under construction in TL region since 2011. The electrolysis plant to be completed provides an annual production capacity of 350 kton aluminum, but requires an additional 610 MW power supply according to plant specifications. This results in a gap between the power generation and demand, since the load will be increased to $1602 \mathrm{MW}$, which is much higher than the current generation capacity.

There are three possible solutions to fill the gap between the generation and demand:

1. Abandon the investment on the electrolysis plant under construction. This solution would result in an investment loss of over 4 billion $\mathrm{RMB}(6.5 \mathrm{RMB} \approx 1$ USD) and more significantly, it reduces the investor's competitiveness for the growing aluminum market in China.

2. Purchase electricity from state grid company. This solution requires huge investments in a transmission system since the electrolysis plant is distant away from the periphery of the state grid. In addition, the electricity price from the state grid is $0.4456 \mathrm{RMB} / \mathrm{kWh}$. Such a high price significantly reduces the profitability of the electrolysis plant because the cost of electricity accounts for $25 \%-30 \%$ of the total cost for aluminum electrolysis [28].

3. Utilize local resources to satisfy the additional power demand. This solution is attractive for the investor since the utilization of local resources might also help reduce the electrolysis cost. Also, the exploitation of sustainable energy is encouraged by China's government [1], so the investor might obtain additional tax incentive benefits from the investment. Considering TL is rich in both coal and wind resources, the investor hence carefully reviewed both resources, as discussed in the next subsections. 


\subsection{The Coal Resource}

In ZHZE County, the amount of opencast coal reserves has been proven to be over 1740 Mton, 945 Mton of which is exploitable. Although ZHZE County is rich in coal, the local government still has set up strict policy regulations on the exploitation of coal mines due to the local environmental protection pressure. The maximum coal production is thus limited at $15 \mathrm{Mton} / \mathrm{year}$ to ensure the development of ZHZE County. With this limitation, all of the thermal coal has already been purchased through futures contracts and will be sold in the coal market in pursuit of higher profit. The isolated power system cannot purchase any more thermal coal from the local market.

Although the purchase of thermal coal is limited, low-grade coal, which is not profitable when sold into the market, is allowed to be traded freely. The isolated power system is hence able to purchase low-grade coal from the local market so as to satisfy part of the additional generation demand. However, due to the lower heating value of low-grade coal, power plants require longer coal grinding processes and extra processes in order to enhance the coal combustion, so additional auxiliary power is needed, and then the auxiliary power ratio of low-grade-coal fired power plants is raised from $8.5 \%$ to $12 \%$ of generator capacity compared with thermal coal fired power plants. This increases the unit generation cost so that low-grade-coal-powered plants are not as economic as thermal-coal-powered plants.

\subsection{The Wind Resource}

In addition to coal resources, ZHZE is also rich in wind resources, which can be demonstrated according to the measurements recorded by a local anemometer. As shown in Figure 1, the areas circled by " $\mathrm{A} \rightarrow \mathrm{M}$ " and " $1 \rightarrow 4$ " are two areas reserved for the potential construction of two wind farms in the future. The anemometer remarked as "\#5388" is close to both areas and it records the wind speed at the heights of 10,30,50 and $70 \mathrm{~m}$, respectively. The monthly wind speeds of ZHZE are as listed in Table 2.

Figure 1. The geographical position of anemometer " $5388 \#$ ".

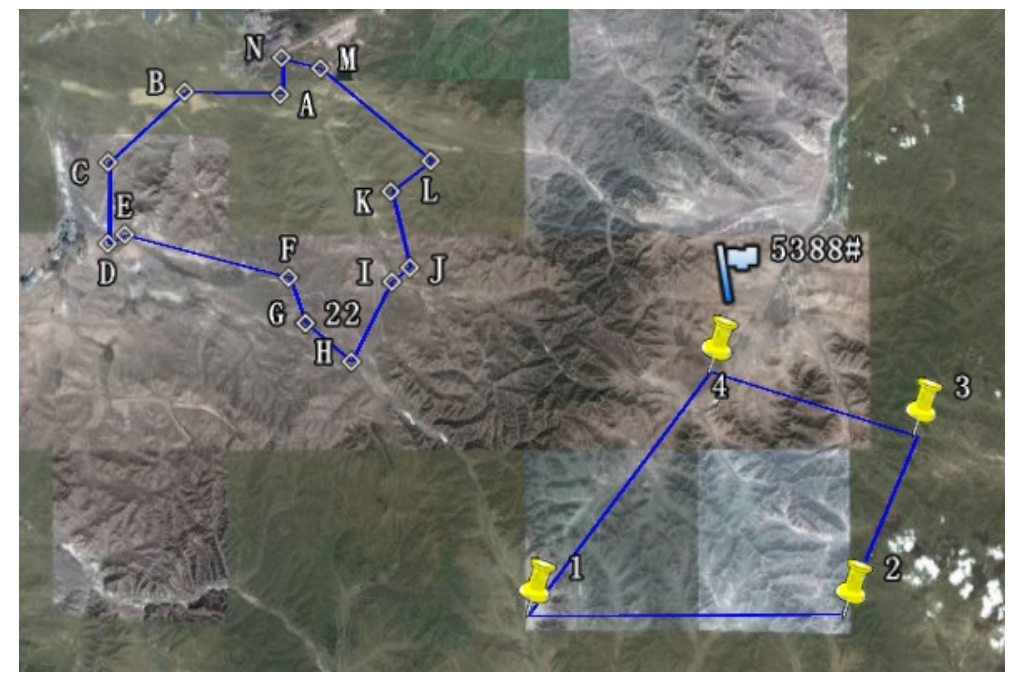


Table 2. The monthly-average wind speed in 2009 as measured by the \#5388 anemometer.

\begin{tabular}{cccccccccccccc}
\hline Height & JAN & FEB & MAR & APR & MAY & JUN & JUL & AUG & SEP & OCT & NOV & DEC & Average \\
\hline $70 \mathrm{~m}$ & 8.91 & 8.21 & 8.51 & 7.62 & 7.92 & 7.55 & 5.43 & 6.58 & 7.65 & 6.88 & 8.12 & 8.90 & 7.67 \\
$50 \mathrm{~m}$ & 8.50 & 7.94 & 8.50 & 7.50 & 7.73 & 7.47 & 5.38 & 6.51 & 7.54 & 6.86 & 8.07 & 9.40 & 7.59 \\
$30 \mathrm{~m}$ & 8.54 & 7.84 & 8.21 & 7.26 & 7.45 & 7.23 & 5.13 & 6.24 & 7.17 & 6.49 & 7.67 & 9.03 & 7.33 \\
$10 \mathrm{~m}$ & 7.77 & 7.05 & 7.67 & 6.67 & 6.72 & 6.50 & 4.50 & 5.51 & 6.42 & 5.89 & 7.13 & 8.10 & 6.63 \\
\hline
\end{tabular}

According to the measurement, the maximum wind speed is higher than $8 \mathrm{~m} / \mathrm{s}$ in the winter season, and the minimum wind speed is higher than $6 \mathrm{~m} / \mathrm{s}$ in the summer season. On average, the annual wind speed is $7.6 \mathrm{~m} / \mathrm{s}$, which corresponds to 6th level ("best-quality") wind according to the "The wind resource assessment method of wind farms" (GB/T18710-2002) [29]. The instantaneous wind speed mainly concentrates within the valid wind speed region, which is defined between the cut-in and cut-out wind speed, normally from 3 to $25 \mathrm{~m} / \mathrm{s}$ for a wind turbine. As shown by the statistical data in Table 3, there are over $7000 \mathrm{hrs}$, or $80 \%$ duration per year, in which the wind speed at $70 \mathrm{~m}$ is within the valid wind speed region. Thus, wind turbines can effectively produce power during most of a year.

Based on the investigation of local wind resource, it is feasible to utilize the local wind power as a main power source for the electrolysis plant. However, since wind is stochastic and intermittent, wind generators harvest energy only when wind is available. Hence, wind farms cannot fully satisfy the load demand in the low wind periods and still cannot solve the problem of generation deficiency. Thus, one practical solution is building additional low-grade-coal-fired power plants to supplement the intermittent wind power.

Table 3. The duration within the valid wind speed region.

\begin{tabular}{cccc}
\hline Height & $\begin{array}{c}\text { Hours within } \\
\mathbf{3 - 2 5} \mathbf{~ m} / \mathbf{s}\end{array}$ & $\begin{array}{c}\text { Hours within } \\
\mathbf{4 - 2 5} \mathbf{~ m} / \mathbf{s}\end{array}$ & $\begin{array}{c}\text { Hours within } \\
\mathbf{5 - 2 5} \mathbf{~ m} / \mathbf{s}\end{array}$ \\
\hline $70 \mathrm{~m}$ & 7030 & 6382 & 5776 \\
$50 \mathrm{~m}$ & 6938 & 6296 & 5692 \\
$30 \mathrm{~m}$ & 6765 & 6168 & 5524 \\
$10 \mathrm{~m}$ & 6575 & 6011 & 5406 \\
\hline
\end{tabular}

\subsection{The Wind-Coal Hybrid Energy System}

A wind-coal hybrid system is hence suggested as the final solution for the power supply of the electrolysis plant. The added hybrid system includes two $400 \mathrm{MW}$ wind farms located on the reserved areas shown in Figure 2 and $2 \times 350$ MW low-grade-coal-fired power plant as back-up for the intermittent wind generation. This solution is quite attractive for the investor because wind generation might substantially reduce the electrolysis cost considering the zero operational cost of wind. During the low wind period duration, the low-grade coal-fired generation can also fill the generation gap. The structure of this system is as shown in Figure 2, in which the yellow blocks represent the components added after the system expansion. 
Figure 2. The structure of the isolated power system.

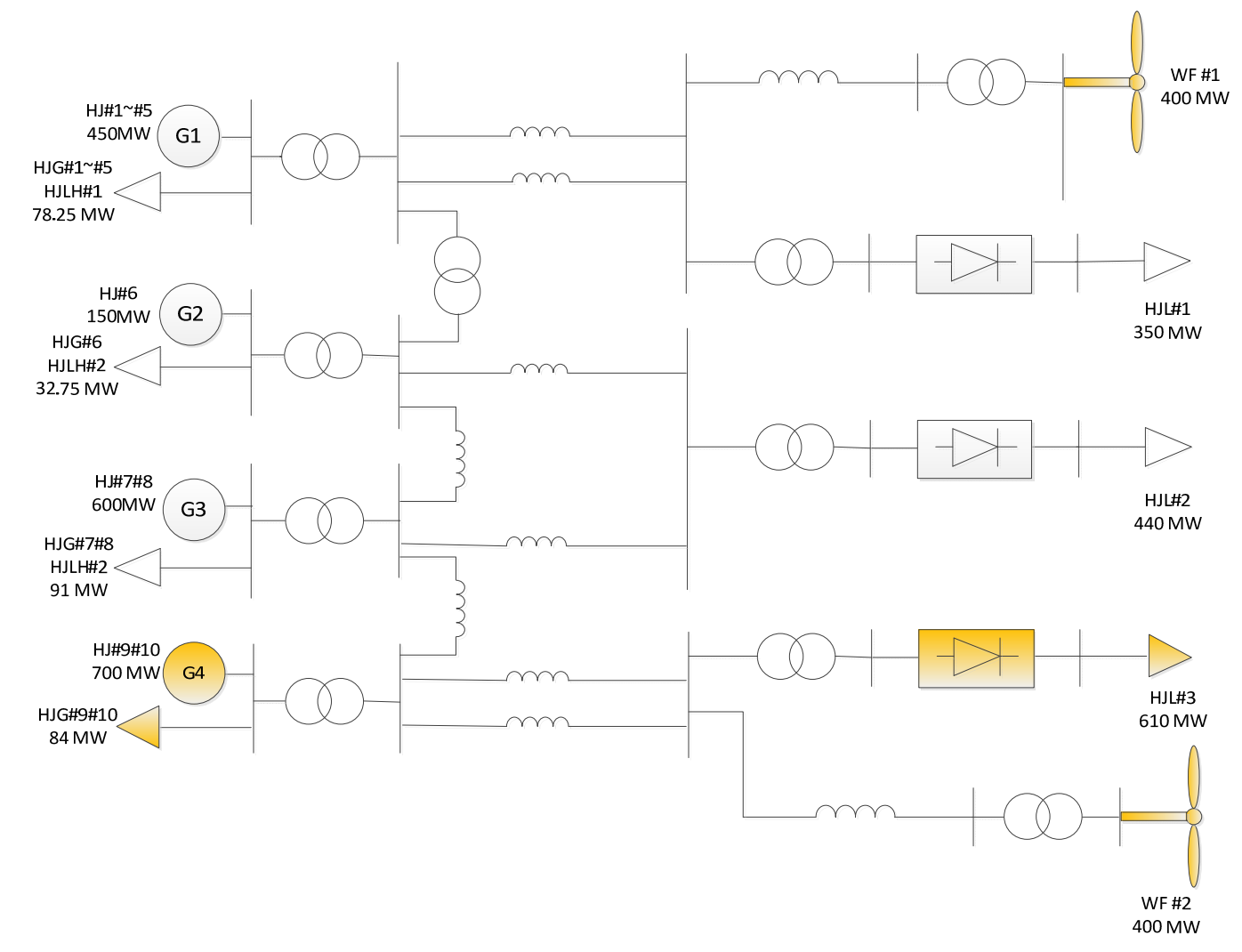

The characteristics of main components are briefly described as follows:

1. Coal-fired power plants. There are four coal-powered power plants. G1 G3 are thermal-coalpowered and have already been constructed. The total capacity of G1 which contains five generators $\mathrm{HJ} \# 1 \sim \mathrm{HJ} \# 5$ is $450 \mathrm{MW}$. G2 is rated at $150 \mathrm{MW}$ with only one unit, HJ\#6. G3 contains two $300 \mathrm{MW}$ generators numbered as HJ\#7 and HJ\#8 respectively. G4 is a new plant to be built for the expanded aluminum production. It has two generators: HJ\#9 and HJ\#10, both of which are $350 \mathrm{MW}$ low-grade-coal-fired generators. These four power plants are all controlled by a central dispatch center.

2. Load. The main load in this system is aluminum electrolysis load, $1400 \mathrm{MW}$ in total. Among them, HJL\#1 and HJL\#2 have already been constructed and HJL\#3 is a new electrolysis plant under construction. The electrolysis plants are driven by DC current so they are connected with the grid through a diode-rectifier. In addition to electrolytic DC load, there are also $100 \mathrm{MW}$ AC heating load and a total of $186 \mathrm{MW}$ auxiliary AC power for the coal-powered power plants. In terms of auxiliary power with respect to the total power plant capacity, the ratio is $8.5 \%$ for thermal-coal-fired plants and $12 \%$ for low-grade-coal-fired plants respectively.

3. Wind Farm. Two DFIG-based wind farms are connected to this system. Each of them has 400 MW capacity. They are about to be constructed on the reserved areas as shown in Figure 1.

After the expansion on both the generation and load sides, the generation capacity will be increased to $1900 \mathrm{MW}$ for coal-powered generators and the overall generation capacity is increased to $2700 \mathrm{MW}$ after the wind generation is taken into account. Theoretically, such a generation capacity is enough to 
cover the electrolytic DC load of $1400 \mathrm{MW}$ as well as the auxiliary AC load of $286 \mathrm{MW}$. However, considering the wind-load penetration will be over $800 / 1686 \approx 67 \%$, it is technically difficult to integrate such a high percentage of wind power into an isolated power system from the operational aspect. Also, in order to guarantee the investment return, the profitability of this wind-coal hybrid system should be carefully examined from the financial aspect considering the relatively higher investment for the construction of wind farms and the low-grade-coal-fired power plants. These technical and economic issues will be addressed in detail in the next sections.

\section{The Technical Demonstration on the Power Balancing of the Isolated System}

One major technical issue is how to maintain power balance within this isolated system. Since the power system is distant from the inter-connected state grid, the system will have a wind penetration level over $47 \%$, but without any external-grid support. The power balancing of the proposed isolated system should be carefully investigated. This section hence discusses the technical feasibility of this proposal by analyzing the power balance in some typical meteorological scenarios.

\subsection{The Controllability of System Components for Power Balancing}

\subsubsection{Electrolytic Load}

As shown in Figure 2, the electrolytic load is connected with grid through a diode rectifier and a transformer. It is difficult to control the diode rectifier system to respond to the grid frequency variation, but the rectifier's DC output voltage can still be adjusted by the transformer tap changer to enable the electrolytic plant to participate in the power balancing control. The secure adjustment region is as low as $-10 \%$ of rated capacity according to the technical specifications provided by the manufacturer. This means that it is technically safe to reduce the electrolytic load by $1400 \times 10 \%=140 \mathrm{MW}$ and avoid load shedding.

\subsubsection{Heating Load}

Heating load is temperature dependent. Normally, the peak consumption of $100 \mathrm{MW}$ occurs in winter, early spring and late autumn. And in summer season, there is no requirement for supplying heat.

\subsubsection{Wind Generator}

With present technologies, wind generators are still "semi-participants" in power balancing control. It is because wind generators are only able to reduce the power output, but find it difficult to increase the power output due to their aerodynamic limitations [30]. Therefore, the wind generation becomes the main fluctuation source causing power imbalances in the system.

\subsubsection{Coal-Fired Generator}

Coal-fired generators have full capacity of participating in the power balancing control. Still, there are two limitations. Firstly, the power output must be within a valid region. The maximum output is the rated capacity and the minimum output of each generator is listed in Table 4. In total, the minimum 
power output should be higher than $925 \mathrm{MW}$ if all the coal-powered generators are in service. Secondly, the ramping speed is limited for each generator as shown by Table 5. Ramping rate represents a unit's power increasing capability (positive ramping) and the decreasing capability (negative ramping). In this isolated system, the ramping rate of generators should be ensured to be faster than the ramping rate of fluctuation sources, such as the wind power output, in order to keep the system power and load in balance.

Table 4. The minimum power output of generators.

\begin{tabular}{ccccc}
\hline $\begin{array}{c}\text { Power } \\
\text { Plants }\end{array}$ & Generators & $\begin{array}{c}\text { Capacity } \\
(\text { MW) }\end{array}$ & $\begin{array}{c}\text { Minimum } \\
\text { output ratio }\end{array}$ & $\begin{array}{c}\text { Minimum power } \\
\text { output (MW) }\end{array}$ \\
\hline G1 & HJ\#1, HJ\#2 & $50 \times 2$ & $60 \%$ & 60 \\
G1 & HJ\#3, HJ\#4 & $100 \times 2$ & $60 \%$ & 120 \\
G1 & HJ\#5 & 150 & $53.3 \%$ & 80 \\
G2 & HJ\#6 & 150 & $53.3 \%$ & 80 \\
G3 & HJ\#7, HJ\#8 & $300 \times 2$ & $45 \%$ & 270 \\
G4 & HJ\#9, HJ\#10 & $350 \times 2$ & $45 \%$ & 315 \\
& & In total & & $\mathbf{9 2 5}$ \\
\hline
\end{tabular}

Table 5. The maximum ramping rate of generators.

\begin{tabular}{ccc}
\hline Capacity & $\begin{array}{c}\text { Maximum positive } \\
\text { ramping rate (MW/5 min) }\end{array}$ & $\begin{array}{c}\text { Maximum negative } \\
\text { ramping rate (MW/5 min) }\end{array}$ \\
\hline $50 \mathrm{MW}$ & 0.92 & -11.25 \\
$100 \mathrm{MW}$ & 10.00 & -10.00 \\
$150 \mathrm{MW}$ & 11.67 & -17.50 \\
$300 \mathrm{MW}$ & 27.50 & -27.50 \\
$350 \mathrm{MW}$ & 32.10 & -32.10 \\
\hline
\end{tabular}

\subsection{The Investigation on Power Balancing in Extreme Scenarios}

The profitability of the project strongly depends on a reliable, non-intermittent power supply to the electrolytic load. However, at a wind penetration level of $47 \%$, any intensive wind power fluctuation might result in a system imbalance, which has been considered as one major factor that can cause load shedding or even blackouts. The power imbalance should be appropriately addressed by the coordination of the entire system. This subsection hence discusses whether the proposed wind-coal hybrid system is capable of maintaining the power balance at such a high wind penetration level.

\subsubsection{Wind Power Profile}

With the wind speed measurements from the "\#5388" anemometer as input, the power output from the two wind farms can be roughly estimated according to the computation result from WAsP [31], which is a widely-accepted software in the field of wind farm design. The estimated power output in 2008 is plotted in Figure 3 and three special days are subsequently selected for the examination of system balance. These days include the day with the highest average output of wind power, the day with the lowest average output of wind power and the day with the highest wind power ramping rate. 
The system capability of maintaining power balance can be evaluated based on the investigation of these extreme scenarios.

Figure 3. The wind power output in 2008.

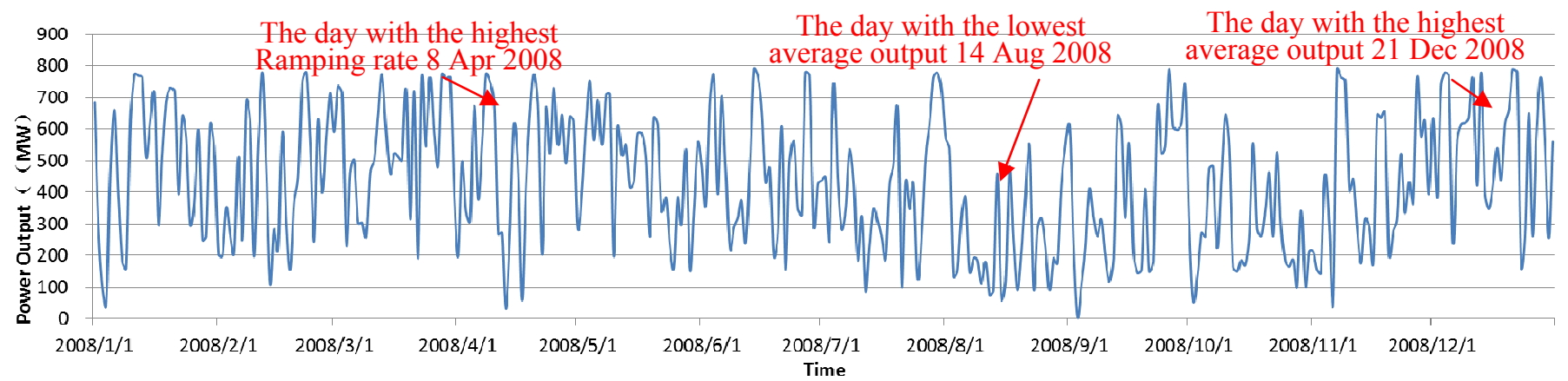

\subsubsection{The Day with the Highest Average Output of Wind Power}

The day with the highest average wind power output is 21 December 2008. The highest wind power output also means the highest possibility that wind curtailment will occur if the entire load demand is less than the sum of wind generation and the minimum output of coal-fired generators. The purpose for selecting the day is hence on examining whether or how much the wind spillage might occur and whether the system design should be adjusted if the wind curtailment becomes unacceptable. As shown in Figure 4, the estimated load is $1686 \mathrm{MW}$ in total, including $1400 \mathrm{MW}$ electrolytic load, $100 \mathrm{MW}$ heating load and 186 MW auxiliary power load.

Figure 4. The load profile on 21 December 2008.
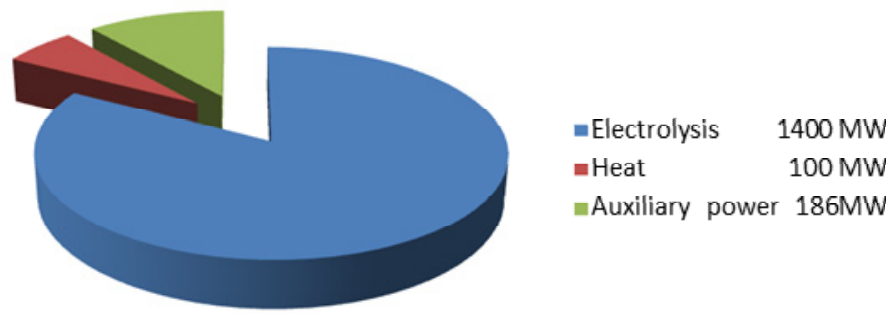

The power output of wind and coal-fired generators are plotted in Figure 5 and zoomed in Figure 6. Figure 5 indicates that the wind-coal hybrid system is able to satisfy the load consumption of $1686 \mathrm{MW}$. However, since the total generation from wind and the minimum output of coal generators exceeds the total load, around $30 \mathrm{MW}$ wind power should be curtailed in order to keep the system balanced as shown in Figure 6, which is a zoomed view for from 15:00 to 24:00. The curtailed wind power is only less than $30 / 800=3.75 \%$ compared to the wind farm rated capacity. The wind spillage accounts for only a little part of the entire generation capacity. This verifies that the ratio of wind generation within the hybrid system is appropriately designed. 
Figure 5. The power output of wind and coal generators in 21 December 2008.

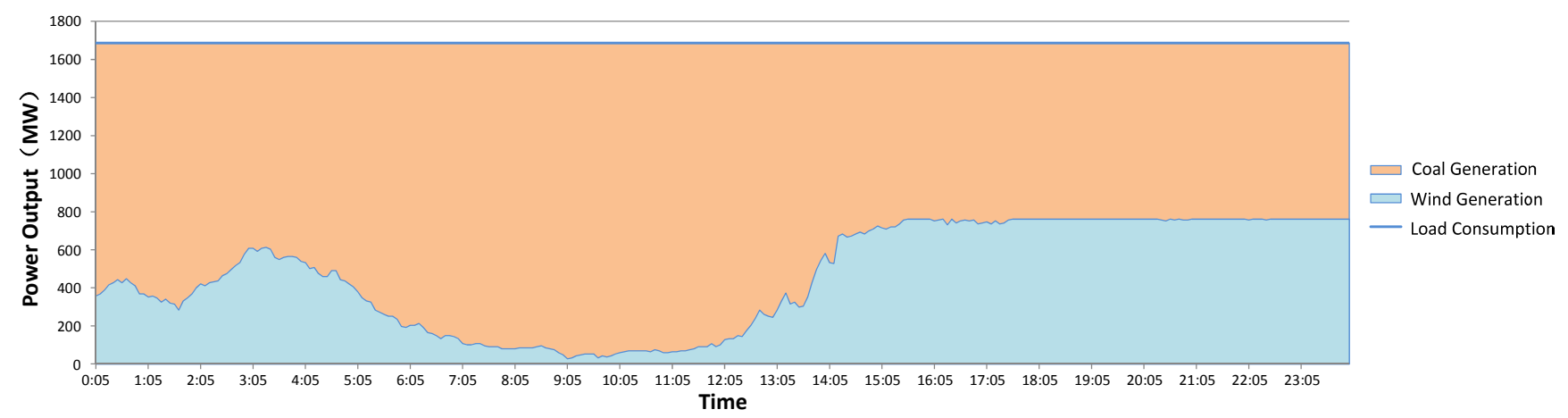

Figure 6. The wind curtailment of wind farms in 21 December 2008.

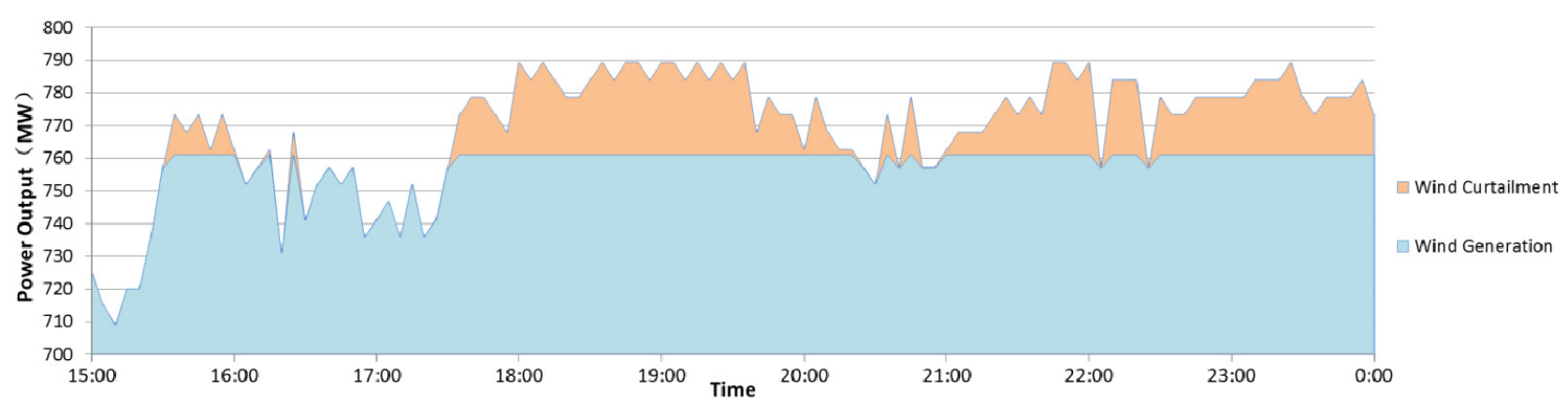

\subsubsection{The Day with the Lowest Average Output of Wind Power}

The day with the lowest average output of wind power is 14 August 2008. The purpose of selecting the day is to examine whether the load demand can be satisfied by hybrid wind-coal generation. As shown in Figure 7, the estimated load is $1586 \mathrm{MW}$ in total, including $1400 \mathrm{MW}$ electrolytic load and $186 \mathrm{MW}$ auxiliary power load. Heating load is not considered since the day occurs in the summer season.

Figure 7. The load profile on 14 August 2008.

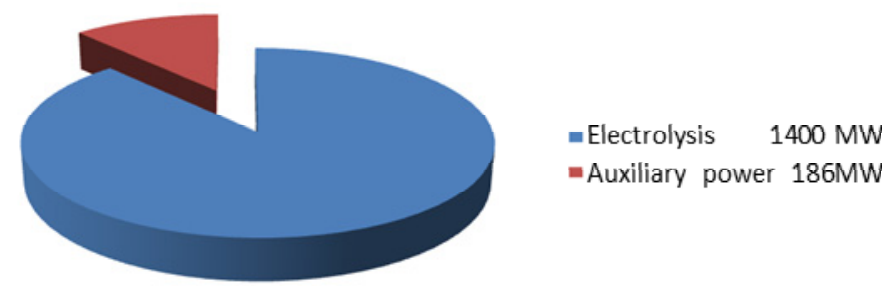

Figure 8 shows that the wind-coal generation is capable of supplying the electrolysis plant. Even though there is no wind output, the coal-powered generators can still meet the overall load demand when all the generators are in service. In practice, another common scenario is that one generator is out of service due to maintenance or some other reason. The most serious situation is that the largest generator, HJ\#9 of $350 \mathrm{MW}$ in this paper, goes out of service. The scenario is simulated and plotted in Figure 9. According to the simulation result, a load reduction of $35 \mathrm{MW}$ will ensure the system balance. The reduction of $35 \mathrm{MW}$ load is within the secure adjustment region of electrolysis plant so it 
would not result in any load shedding events, as discussed in the first part of this section. Therefore, the simulation demonstrates that the overall capacity of coal generators is appropriately designed for the proposed wind-coal hybrid system.

Figure 8. The power output of wind and coal generators on 14 August 2008 while all generators are online.

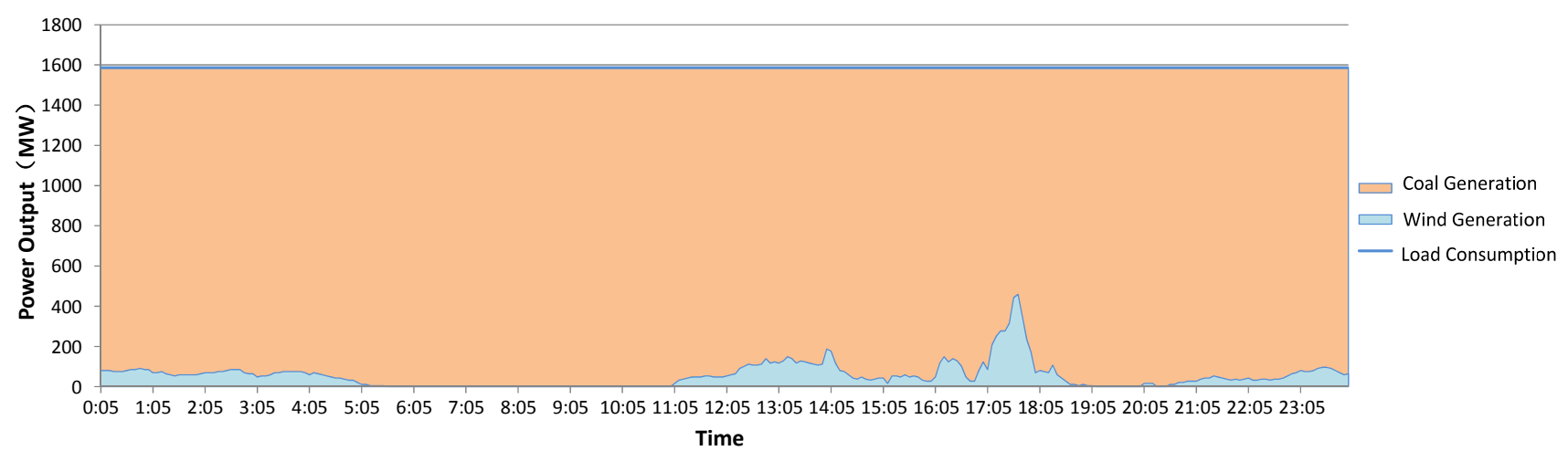

Figure 9. The power output of wind and coal generators on 14 August 2008 assuming that HJ\#9 generator is offline.

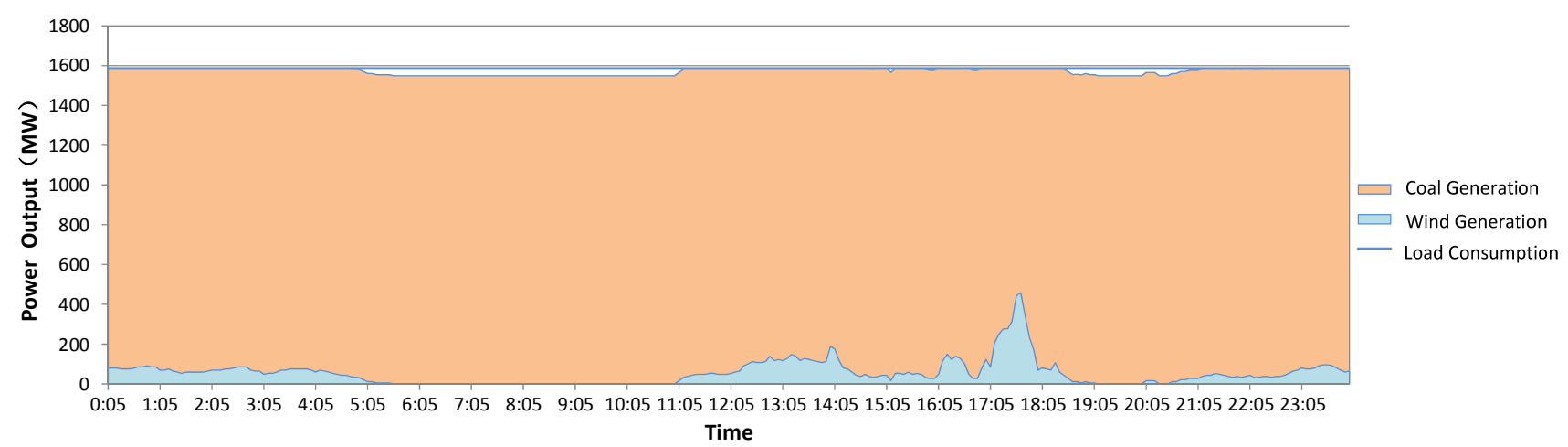

\subsection{The Day with the Highest Ramping Rate of Wind Power}

The day with the highest ramping rate of wind power is 8 April 2008. The purpose for selecting the day is on examining whether the power output of coal generators can ramp fast enough to track the stochastic variation of wind power.

Figure 10. The load profile in 8 April 2008.

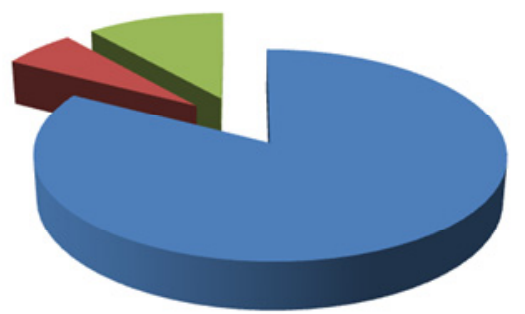


As shown in Figure 10, the estimated load is $1686 \mathrm{MW}$ in total, including $1400 \mathrm{MW}$ electrolysis load, $100 \mathrm{MW}$ heating load and $186 \mathrm{MW}$ auxiliary power load. Figure 11 plots the wind power output on the day of 8 April 2008 and it shows that the highest power fluctuation, which is as fast as $283 \mathrm{MW} / 5$ minutes, happens from 8:50 to 9:30. When the coal generators are all in service, the overall ramping rate is fast enough to compensate for the wind power fluctuation. Figure 12 shows the power output of each generator through a calculation based on the ramping rates. According to Figure 12, the maximum ramping rate is computed for each generator as listed in Table 6, which indicates that both the positive and the negative ramping are lower than the technical limitations for all the online generators. It demonstrates that the installed generators are capable of handling the most intensive wind power fluctuation if the entire system is under normal operation.

Figure 11. The power output of wind and coal generators on 8 April 2008 while all generators are online.

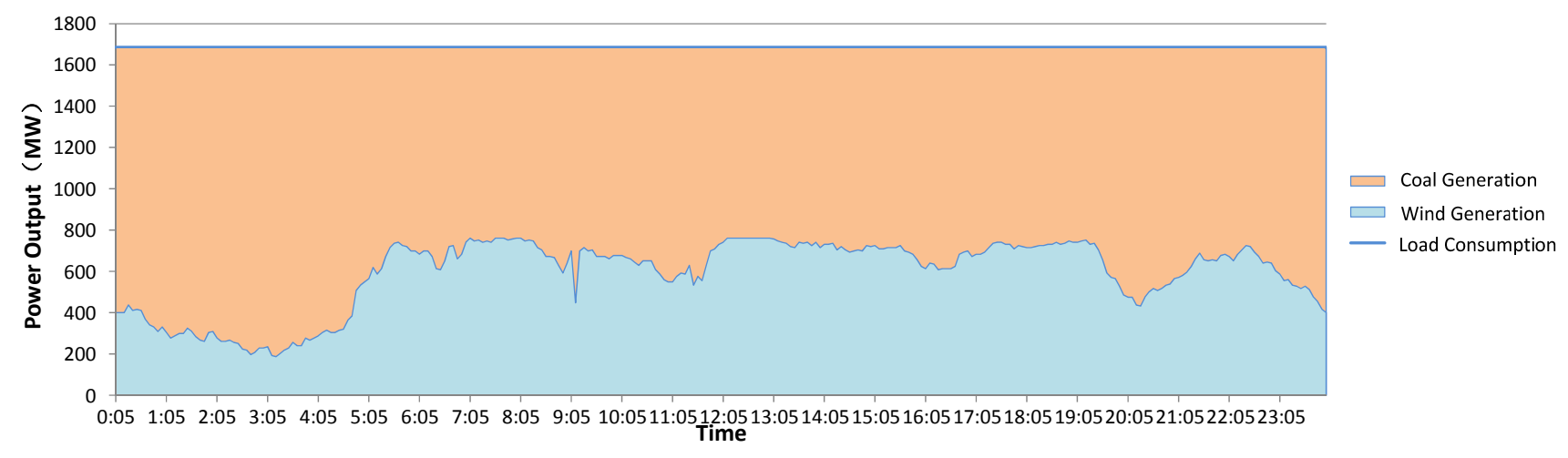

Figure 12. The power output of coal generators on 8 April 2008 while all generators are online.

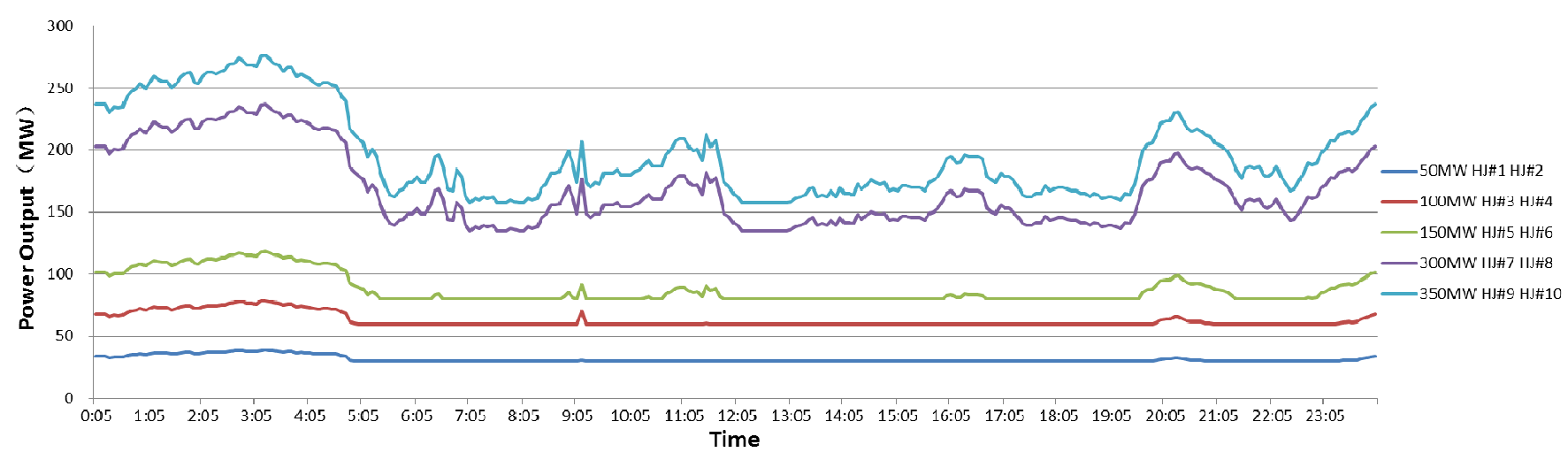


Table 6. The statistics of positive/negative ramping rate while all generators are online.

\begin{tabular}{ccccc}
\hline Capacity & $\begin{array}{c}\text { Maximum positive } \\
\text { ramping rate } \\
\text { (MW/5 min) }\end{array}$ & $\begin{array}{c}\text { Maximum negative } \\
\text { ramping rate } \\
\text { (MW/5 min) }\end{array}$ & $\begin{array}{c}\text { Positive ramping } \\
\text { rate limitation } \\
\text { (MW/5 min) }\end{array}$ & $\begin{array}{c}\text { Negative ramping } \\
\text { rate limitation } \\
\text { (MW/5 min) }\end{array}$ \\
\hline $50 \mathrm{MW}$ & 0.92 & -3.24 & 0.92 & -11.25 \\
$100 \mathrm{MW}$ & 5.34 & -10.00 & 10.00 & -10.00 \\
$150 \mathrm{MW}$ & 11.67 & -11.67 & 11.67 & -17.50 \\
$300 \mathrm{MW}$ & 27.50 & -27.50 & 27.50 & -27.50 \\
$350 \mathrm{MW}$ & 32.10 & -32.10 & 32.10 & -32.10 \\
\hline
\end{tabular}

However, if the largest generator, HJ9\#, is out of service, the overall ramping rate is not as fast as the rate of wind power variation according to the simulation results in Figures 13-15. This is because the maximum positive ramping rate, as listed in Table 7 , has reached the upper limit for each online generator.

Figure 13. The power output of wind and coal generators on 8 April 2008 while the HJ\#9 generator is offline.

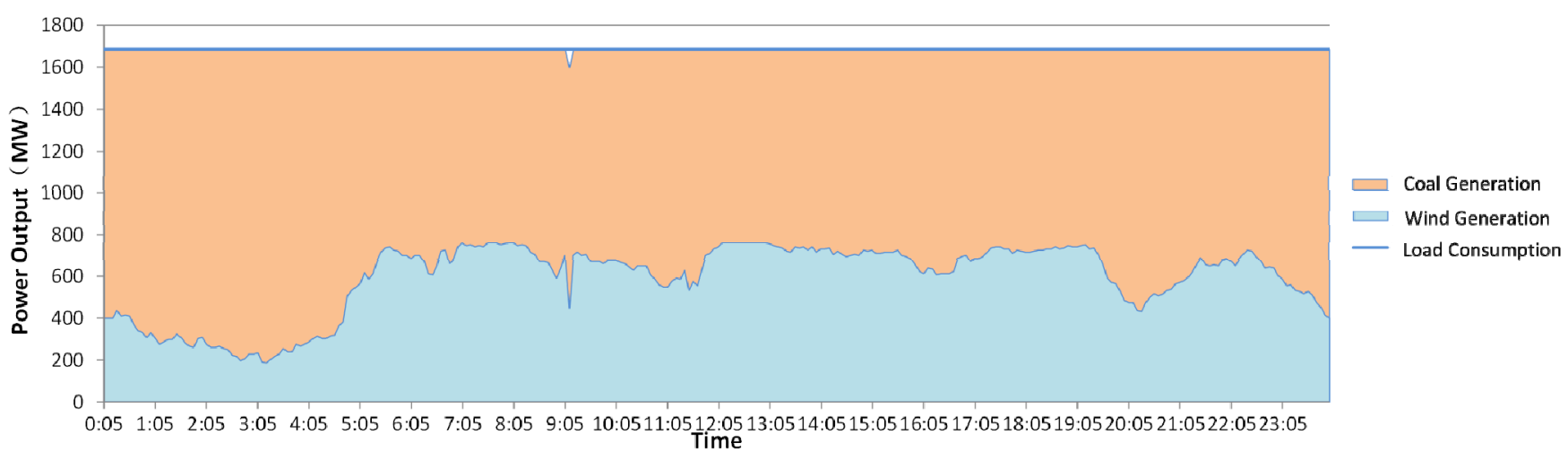

Figure 14. The load reduction on 8 April 2008 while HJ\#9 is offline.

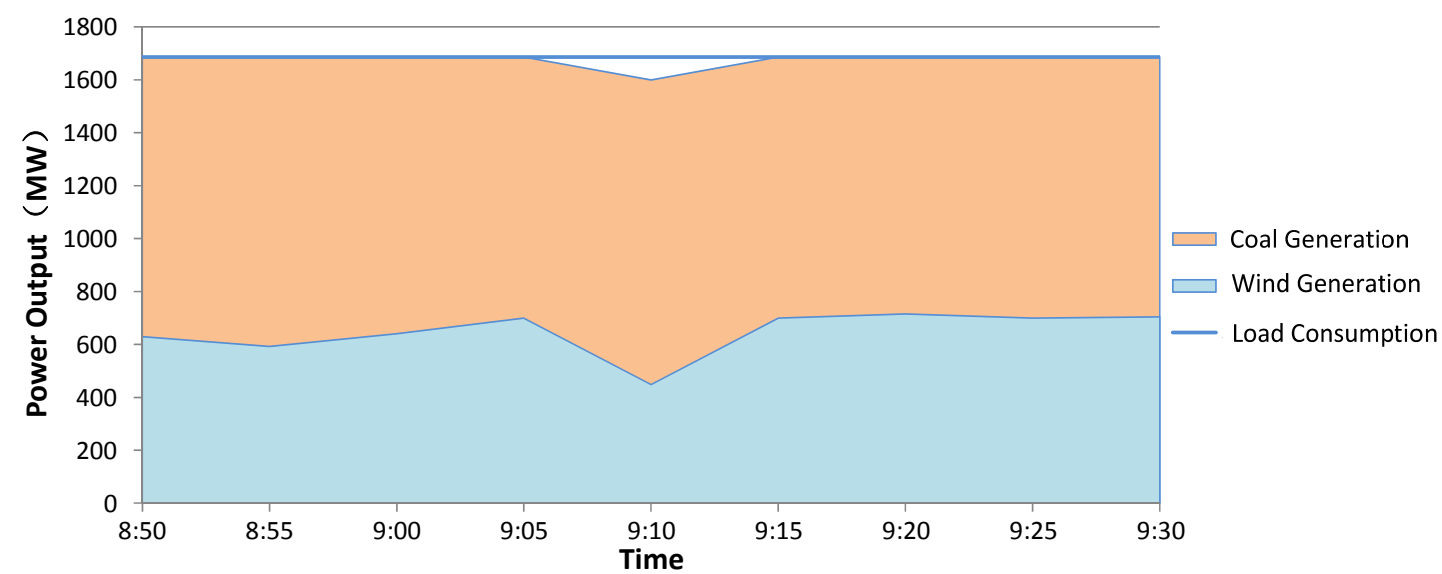


Figure 15. The power output of other coal generators on 8 April 2008 while HJ\#9 generator is offline.

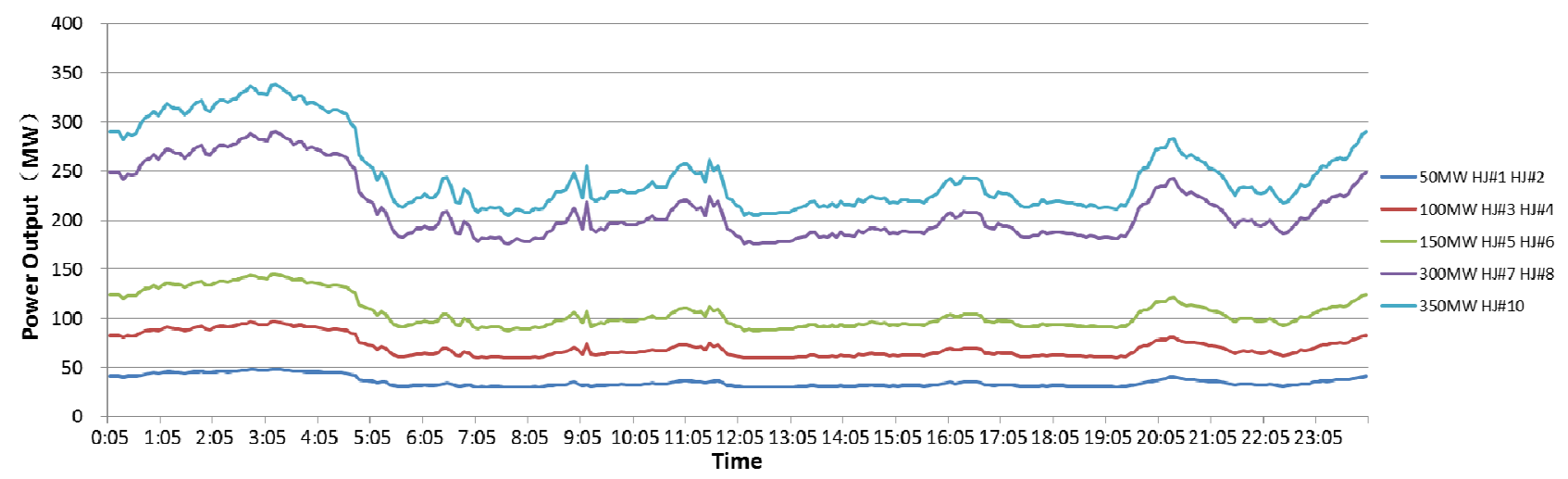

Table 7. The statistics of positive/negative ramping rate while $\mathrm{HJ} \# 9$ generator is offline.

\begin{tabular}{ccccc}
\hline Capacity & $\begin{array}{c}\text { Maximum positive } \\
\text { ramping rate } \\
\text { (MW/5 min) }\end{array}$ & $\begin{array}{c}\text { Maximum negative } \\
\text { ramping rate } \\
\text { (MW/5 min) }\end{array}$ & $\begin{array}{c}\text { Positive ramping } \\
\text { rate limitation } \\
\text { (MW/5 min) }\end{array}$ & $\begin{array}{c}\text { Negative ramping } \\
\text { rate limitation } \\
\text { (MW/5 min) }\end{array}$ \\
\hline $50 \mathrm{MW}$ & 0.92 & -3.97 & 0.92 & -11.25 \\
$100 \mathrm{MW}$ & 10.00 & -10.00 & 10.00 & -10.00 \\
$150 \mathrm{MW}$ & 11.67 & -15.26 & 11.67 & -17.50 \\
$300 \mathrm{MW}$ & 27.50 & -27.50 & 27.50 & -27.50 \\
$350 \mathrm{MW}$ & 32.10 & -32.10 & 32.10 & -32.10 \\
\hline
\end{tabular}

Though the available generation is limited, the isolated system can still compensate most of the wind power fluctuation and the unmet electrolysis load is about $118.7 \mathrm{MW}$, which is less than $144 \mathrm{MW}$, the maximum allowable reduction for electrolysis plant. Therefore, the most serious wind power fluctuation would only result in a temporary load reduction and a permanent load shedding or blackout event can be avoided. Considering that there is very little possibility that an intense wind fluctuation will coincide with a generator trip or maintenance on the same day, no additional generation is required for this isolated system in order to keep the overall power balance, based on the simulation results.

Through the above analysis, the power balance issue of the isolated system has been fully discussed and addressed. The entire system is demonstrated to be capable of satisfying the load demand from the electrolysis plant, in the scenarios of the highest average output, the lowest average output or the highest ramping rate wind power. Even if the largest generator is out of service, the system balance can still be maintained by a temporary load reduction of the electrolysis plant. There is very little possibility that load shedding or system blackouts will happen. Therefore, the isolated system is technically feasible to be operated under a wind penetration level at $47 \%$ and the proposed hybrid system is appropriately designed. 


\section{The Economic Feasibility-An Analysis of the Investment Profitability}

In addition to the technical feasibility, the profitability of the project is another critical factor that affects the investment decision. Currently, the installation cost of wind generators is still higher than the conventional generators, which might reduce the investment return. Thus, the construction cost of $800 \mathrm{MW}$ wind farms should be considered within the entire project investment and a full examination should be undertaken from the financial point of view. Also, the hybrid system contains six sub-systems, which will be described in Section 4.2 in details. Five of them can be operated individually. Therefore operating each of the five individual systems can be regarded as an alternative investment proposal, and the profitability of the composite system should be compared with this alternative proposal in order to verify the economic advantage of the proposed hybrid system.

\subsection{Internal Rate of Return}

In this paper, the internal rate of return (IRR) is selected as a main financial indicator to represent the profitability of the project. The IRR method is better at describing the profitability of an investment than the "present value" method [16] which describes the "return amount" other than the "return efficiency" of an investment. Mathematically, the IRR on an investment or project represents the "rate of return" that makes the net present value (NPV) of all cash flows (both positive and negative) from a particular investment equal to zero [32]. Given the (period, cash flow) pairs $\left(n, C_{n}\right)$, the total number of periods N, and the net present value NPV, the IRR can be found from Equation (1):

$$
N P V=\sum_{n=0}^{N} \frac{C_{n}}{(1+r)^{n}}=0
$$

In reference [32], a good example is also given to help understand the IRR. Based on the above description, the IRR indicator represents the "rate of return" and a higher IRR hence represents higher investment profitability. IRR is also comparable to some other economic rates, for example the nominal interest rate or the annual inflation rate. In China, the nominal interest rate and the annual inflation rate as referred in December 2011, are 3.5\% [33] and 5.4\% [34]. It is convenient to determine the investment profitability by comparing the computed IRR with the interest rate or the annual inflation rate to demonstrate the profitability of an investment proposal.

\subsection{Parameters of the Financial Analysis of the Investment}

The project includes six individual sub-systems. Two of them have been built, including the $1200 \mathrm{MW}$ thermal-coal-powered power plants and $430 \mathrm{kTon}$ electrolysis plant. Four of them are being evaluated, including the $2 \times 400 \mathrm{MW}$ wind farms, the $2 \times 350 \mathrm{MW}$ low-grade-coal-fired power plants, the electrolysis plant of $350 \mathrm{kTon}$ annual production and a $220 \mathrm{kV}$ grid infrastructure for power transmission. Except for the $220 \mathrm{kV}$ grid infrastructure, the other five sub-systems can be operated individually. In this subsection, the IRR for each sub-system is calculated based on the input parameters obtained from the manufacturers. Then the different IRR values are compared with the IRR of the hybrid system for the economic feasibility study. 


\subsubsection{The 1200 MW Thermal-Coal-Fired Power Plants}

The $1200 \mathrm{MW}$ power plants have eight thermal-coal-powered generators, including $2 \times 50 \mathrm{MW}$, $2 \times 100 \mathrm{MW}, 2 \times 150 \mathrm{MW}$ and $2 \times 300 \mathrm{MW}$ generators. If the power plants are operated individually, it has to sell the electricity to the state grid. The annual production of the power plants is estimated at around 5200 hours $\times 1200 \mathrm{MW}=6,240,000 \mathrm{MWh}$, and the purchased price by the state grid is expected to be $0.299 \mathrm{RMB} / \mathrm{kWh}$. Other financial and production parameters are listed in Table 8 . Taking these parameters as input, the economic indicators are computed as shown in Table 9. The asset investment of the power plant costs 5268 Million RMB at the unit construction cost of $4390 \mathrm{RMB} / \mathrm{kW}$ and the IRR of these power plants is $18.02 \%$ and the payback period is 6.47 years.

Table 8. The financial and production parameters for the $1200 \mathrm{MW}$ thermal-coal-powered power plants $(1 \mathrm{RMB} \approx 0.16$ US Dollar).

\begin{tabular}{ccc}
\hline Item & Unit & Quantity \\
\hline Capital ratio & $\%$ & 20 \\
Loan ratio & $\%$ & 80 \\
Loan interest rate & $\%$ & 5.36 \\
Repayment period & year & 15 \\
Annual energy production & $\mathrm{GWh}$ & 3500 \\
Auxiliary power ratio & $\%$ & 8.5 \\
Standard coal price & $\mathrm{RMB} / \mathrm{Ton}$ & 300 \\
Unit coal consumption & $\mathrm{g} / \mathrm{kWh}$ & 317 \\
Desulfurizer price & $\mathrm{RMB} / \mathrm{Ton}$ & 60 \\
Depreciation period & year & 15 \\
Residual value rate & $\%$ & 5 \\
Deposit rate for overhauls & $\%$ & 2 \\
Employee number & person & 234 \\
Average salary & $\mathrm{RMB} / \mathrm{year} /$ person & 50,000 \\
Average bonus rate & $\%$ & 60 \\
Material fee & $\mathrm{RMB} / \mathrm{MWh}$ & 6 \\
Other fee & $\mathrm{RMB} / \mathrm{MWh}$ & 12 \\
\hline
\end{tabular}

Table 9. The evaluation result for the $1200 \mathrm{MW}$ thermal-coal-powered power plants. (1 RMB $\approx 0.16$ U.S. Dollar).

\begin{tabular}{cccc}
\hline No & Item & Unit & Quantity \\
\hline 1 & Generation Capacity & MW & 1200 \\
2 & Asset Investment & Million RMB & 5268 \\
3 & Unit Construction Cost & RMB $/ \mathrm{kW}$ & 4390 \\
4 & Internal Return of Rate & $\%$ & 18.02 \\
5 & Payback Period & Year & 6.47 \\
\hline
\end{tabular}




\subsubsection{The Electrolysis Plant of 430 kTon Annual Production}

The electrolysis plant provides an annual production capacity of $430 \mathrm{kTon}$. If the electrolysis plant is operated individually, it can purchase the electricity from the $1200 \mathrm{MW}$ power plants at $0.299 \mathrm{RMB} / \mathrm{kWh}$, the state grid purchase price, and sell the aluminum in the market at the price of 16,000 RMB/Ton. Other financial and production parameters are listed in Table 10. Taking these parameters as input, the economic indicators are computed as shown in Table 11. The asset investment of the electrolyzation plant is 6,595.53 Million RMB at the unit construction cost of $15,338 \mathrm{RMB} / \mathrm{Ton}$ and the IRR of the electrolysis plant is $35.32 \%$ and the payback period is 3.78 years. By comparing the same indicators, $18.02 \%$ and 6.47 years of the power plants, it is obvious that the electrolysis plant investment is more valuable than the power plants under current market conditions, so the China Power Investment Corporation is motivated to combine the self-owned power plants with the electrolysis plant in pursuit of higher profits than achievable by selling electricity to the state grid.

Table 10. The financial and production parameters for the electrolysis plant of $430 \mathrm{kTon}$ annual production ( $1 \mathrm{RMB} \approx 0.16$ U.S. Dollar).

\begin{tabular}{ccc}
\hline Item & Unit & Quantity \\
\hline Annual production & kTon & 430 \\
Capital ratio & $\%$ & 20 \\
Loan ratio & $\%$ & 80 \\
Loan interest rate & $\%$ & 5.36 \\
Repayment period & Year & 15 \\
Alumina consumption & Ton/Ton & 1.93 \\
Alumina cost & RMB/Ton & 3016 \\
Electricity consumption & $\mathrm{kWh} /$ Ton & 14,250 \\
Electricity cost & RMB/kWh & 0.299 \\
Anode consumption & Ton/Ton & 0.510 \\
Anode cost & RMB/Ton & 1671 \\
Fluoride consumption & Ton/Ton & 0.022 \\
Fluoride cost & RMB/Ton & 6000 \\
Depreciation period & Year & 15 \\
Residual value rate & $\%$ & 6.33 \\
Deposit rate for overhauls & $\%$ & 1.5 \\
Average salary & RMB/Ton & 250 \\
Average Material fee & RMB/MWh & 50 \\
License fee & RMB/MWh & 200 \\
Management fee & RMB/MWh & 255 \\
\hline
\end{tabular}

Table 11. The evaluation result for the electrolysis plant of 430 kTon annual production (1 RMB $\approx 0.16$ U.S. Dollar).

\begin{tabular}{cccc}
\hline No & Item & Unit & Quantity \\
\hline 1 & Annual Production & kTon & 430 \\
2 & Investment Amount & Million RMB & 6595.53 \\
3 & Unit Construction Cost & RMB/Ton & 15,338 \\
4 & Internal Return of Rate & $\%$ & 35.32 \\
5 & Payback Period & Year & 3.78 \\
\hline
\end{tabular}




\subsubsection{The Electrolysis Plant of 350 kTon Annual Production}

The electrolysis plant under evaluation in this case provides an annual production capacity of $350 \mathrm{kTon}$. If the under-built electrolysis plant is operated individually, it has to purchase the electricity from the state grid since current power generation cannot satisfy the required load demand.

Table 12. The financial and production parameters for the electrolysis plant of $350 \mathrm{kTon}$ annual production ( $1 \mathrm{RMB} \approx 0.16$ U.S. Dollar).

\begin{tabular}{ccc}
\hline Item & Unit & Quantity \\
\hline Annual production & $\mathrm{kTon}$ & 350 \\
Capital ratio & $\%$ & 30 \\
Loan ratio & $\%$ & 70 \\
Loan interest rate & $\%$ & 5.36 \\
Repayment period & year & 15 \\
Alumina consumption & Ton/Ton & 1.93 \\
Alumina cost & $\mathrm{RMB} / \mathrm{Ton}$ & 3016 \\
Electricity consumption & $\mathrm{kWh} / \mathrm{Ton}$ & 14,250 \\
Electricity cost & $\mathrm{RMB} / \mathrm{kWh}$ & 0.430 \\
Anode consumption & Ton/Ton & 0.510 \\
Anode cost & $\mathrm{RMB} / \mathrm{Ton}$ & 1671 \\
Fluoride consumption & Ton/Ton & 0.022 \\
Fluoride cost & $\mathrm{RMB} / \mathrm{Ton}$ & 6000 \\
Depreciation period & year & 15 \\
Residual value rate & $\%$ & 6.33 \\
Deposit rate for overhauls & $\%$ & 1.5 \\
Average salary & $\mathrm{RMB} /$ Ton & 250 \\
Average Material fee & $\mathrm{RMB} / \mathrm{MWh}$ & 50 \\
License fee & $\mathrm{RMB} / \mathrm{MWh}$ & 200 \\
Management fee & $\mathrm{RMB} / \mathrm{MWh}$ & 255 \\
\hline
\end{tabular}

The price charged by the state grid is as high as $0.430 \mathrm{RMB} / \mathrm{kWh}$ and the price of aluminum market is still 16,000 RMB/Ton. Using the financial and production parameters as listed in Table 12, which are almost as the same as Table 10, except electricity cost, the economic indicators are computed as shown in Table 13.

Table 13. The evaluation result for the electrolyzation plant of 350k Ton annual production (1 RMB $\approx 0.16$ U.S. Dollar).

\begin{tabular}{cccc}
\hline No & Item & Unit & Quantity \\
\hline 1 & Annual Production & kTon & 350 \\
2 & Investment Amount & Million RMB & 5100 \\
3 & Unit Construction Cost & RMB/Ton & 14,571 \\
4 & Internal Return of Rate & $\%$ & 5.68 \\
5 & Payback Period & Year & 18.60 \\
\hline
\end{tabular}


The estimated investment costs are around 5100 Million RMB at the unit construction cost of $14,571 \mathrm{RMB} /$ Ton and the IRR of the electrolytic plant is $5.68 \%$ and the payback period is 18.60 years. Obviously, the profit of aluminum electrolysis is quite sensitive to the electricity price. The indicators of this electrolysis plant are much worse than those of the $430 \mathrm{kTon}$ one due to the significant increase of the electricity price. The profitability is even worse than that of the $1200 \mathrm{MW}$ power plants. Thus self-owned power plants are essentially necessary to satisfy the energy demand from the electrolysis plant aimed at reducing the aluminum production cost.

\subsubsection{The $2 \times 400 \mathrm{MW}$ Wind Farms}

The $2 \times 400 \mathrm{MW}$ wind farms are under evaluation, and the corresponding financial and production parameters are listed in Table 14. The economic indicators are computed according to the parameters in Table 14, as shown in Table 15.

Table 14. The financial and production parameters for the $2 \times 400 \mathrm{MW}$ wind farms (1 RMB $\approx 0.16$ U.S. Dollar).

\begin{tabular}{ccc}
\hline Item & Unit & Quantity \\
\hline Capital ratio & $\%$ & 20 \\
Loan ratio & $\%$ & 80 \\
Loan interest rate & $\%$ & 6.14 \\
Repayment period & Year & 15 \\
Annual energy production & GWh & 1840 \\
Depreciation period & Year & 15 \\
Residual value rate & $\%$ & 5 \\
Employee salary & RMB/MWh & 9.81 \\
Maintenance and insurance fee & RMB/MWh & 45.65 \\
Material fee & RMB/MWh & 10 \\
Other fee & RMB/MWh & 12 \\
\hline
\end{tabular}

Table 15. The evaluation result for the $2 \times 400 \mathrm{MW}$ wind farms ( $1 \mathrm{RMB} \approx 0.16$ U.S. Dollar).

\begin{tabular}{cccc}
\hline No & Item & Unit & Quantity \\
\hline 1 & Generation Capacity & MW & 800 \\
2 & Investment Amount & Million RMB & 587,297 \\
3 & Unit Construction Cost & RMB/kW & 7341 \\
4 & Internal Return of Rate & $\%$ & 13.51 \\
5 & Payback Period & Year & 8.81 \\
\hline
\end{tabular}

The unit construction cost for the wind farms is $7341 \mathrm{RMB} / \mathrm{kW}$, as listed in Table 15 , which is much higher than the unit construction cost around $4300 \mathrm{RMB} / \mathrm{kW}$ for coal-fired power plants. If the wind farms sell the electricity to the state grid, the equivalent production hours are estimated at around 2300 hours, which is less than 5200 hours for coal-fired generators due to wind intermittence. Comparing Table 14 with Table 9, if the wind farms are operated individually, it is found that the profitability of wind farms are still not as good as the $1200 \mathrm{MW}$ coal-fired power plants. Even though the price for wind source is zero and the price offered by the state grid is $0.510 \mathrm{RMB} / \mathrm{kWh}$, which is 
much higher than the price of $0.299 \mathrm{RMB} / \mathrm{kWh}$ generated by coal power plants. Therefore it might be a more profitable option to utilize the wind generation to compensate for the power supply shortage for electrolysis load rather than to sell electricity to the state grid.

\subsubsection{The $2 \times 350$ MW Low-Grade-Coal-Fired Power Plants}

If the power plants are operated individually and sell the electricity to the state grid, the annual production is estimated at around 5000 hours $\times 700 \mathrm{MW}=3,500,000 \mathrm{MWh}$, and the purchase price by the state grid is expected at $0.314 \mathrm{RMB} / \mathrm{kWh}$. The other financial and production parameters are listed in Table 16. Most of the parameters are similar to those of the $1200 \mathrm{MW}$ power plants except the auxiliary power ratio. This parameter is $12 \%$ for low-grade-coal-fired generators but is $8.5 \%$ for the thermal-coal-fired generators. From the calculation results in Table 17 the asset investment of the power plant costs 2988.37 Million RMB at the unit construction cost of $4269 \mathrm{RMB} / \mathrm{kW}$. The IRR for the power plant is $12.11 \%$, which is less than that of the wind farm. Thus, the profitability for the power plant is worse than the $800 \mathrm{MW}$ wind farms due to the higher auxiliary power ratio. It increases the unit generation cost so that low-grade-coal-fired plants are more suitable as backup for the wind generation and not good as the main power suppliers for aluminum production.

Table 16. The financial and production parameters for the $2 \times 350 \mathrm{MW}$ low-grade-coal-fired power plants ( $1 \mathrm{RMB} \approx 0.16$ U.S. Dollar).

\begin{tabular}{ccc}
\hline Item & Unit & Quantity \\
\hline Capital ratio & $\%$ & 20 \\
Loan ratio & $\%$ & 80 \\
Loan interest rate & $\%$ & 6.14 \\
Repayment period & year & 15 \\
Annual energy production & $\mathrm{GWh}$ & 3500 \\
Auxiliary power ratio & $\%$ & 12 \\
Standard coal price & $\mathrm{RMB} / \mathrm{Ton}$ & 300 \\
Unit coal consumption & $\mathrm{g} / \mathrm{kWh}$ & 317 \\
Desulfurizer price & $\mathrm{RMB} / \mathrm{Ton}$ & 60 \\
Depreciation period & $\mathrm{Year}$ & 15 \\
Residual value rate & $\%$ & 5 \\
Deposit rate for overhauls & $\%$ & 2 \\
Employee number & person & 234 \\
Average salary & $\mathrm{RMB} / \mathrm{year} /$ person & 50,000 \\
Average bonus rate & $\%$ & 60 \\
Material fee & $\mathrm{RMB} / \mathrm{MWh}$ & 6 \\
Other fee & $\mathrm{RMB} / \mathrm{MWh}$ & 12 \\
\hline
\end{tabular}


Table 17. The evaluation result for the $2 \times 350 \mathrm{MW}$ low-grade-coal-fired power plants (1 RMB $\approx 0.16$ U.S. Dollar).

\begin{tabular}{cccc}
\hline No & Item & Unit & Quantity \\
\hline 1 & Generation Capacity & MW & 700 \\
2 & Investment Amount & Million RMB & 2988.37 \\
3 & Unit Construction Cost & RMB/kW & 4269 \\
4 & Internal Return of Rate & $\%$ & 12.11 \\
5 & Payback Period & Year & 9.2 \\
\hline
\end{tabular}

\subsection{6. $220 \mathrm{kV}$ Grid Infrastructure}

The investment amount of the $220 \mathrm{kV}$ grid infrastructure is estimated at around 1815 Million RMB in total, including 1760 Million RMB for the transmission system and 50 MRBM for the dispatch center. The profitability of the grid will be included in the analysis of the entire system in subsection 4.2.7 since the grid infrastructure cannot return a profit by itself.

\subsubsection{The Composite Isolated Power System}

Using the parameters of Table 8, Table 10, Table 12, Table 14, and Table 16, the isolated power system is evaluated as a composite of the aforementioned six subsystems. The evaluation results are listed in Table 18 and compared with the result of the five sub-systems in Table 19. According to the comparison, the proposed hybrid system is more profitable than almost any of the individual systems (except the case of the electrolytic plant of $430 \mathrm{kTon}$ annual production), even with the additional investment in grid infrastructure taken into account. A quick explanation of the profitability is that the intermediate procedure, selling electricity at a lower price to and purchasing at a higher price from the state grid as shown in Figure 16, is avoided by the proposed composite isolated system. The electrolysis plants are able to purchase the electricity from the self-owned coal power plants at a lower price. Further, the production cost is reduced due to the wind power integration and the final product is sold in the aluminum market, which is currently more profitable than the electricity market.

Figure 16. The intermediate procedure of the state grid (1 RMB $\approx 0.16$ U.S. Dollar).

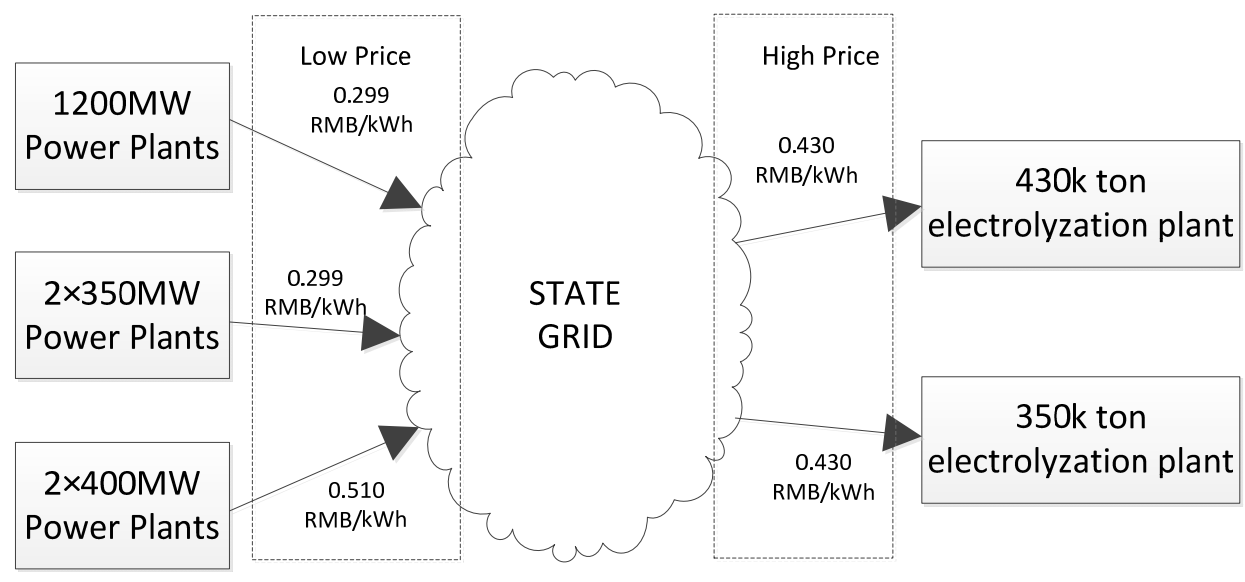


Table 18. The evaluation result for the isolated power system. (1 RMB $\approx 0.16$ U.S. Dollar).

\begin{tabular}{cccc}
\hline No & Item & Unit & Quantity \\
\hline 1 & Coal Generation Capacity & MW & 1900 \\
2 & Wind Generation Capacity & MW & 800 \\
3 & Annual aluminum production & kTon & 780 \\
4 & Asset Amount & Million RMB & 27,685 \\
5 & Internal Return of Rate & $\%$ & 27.17 \\
6 & Payback Period & Year & 5.46 \\
\hline
\end{tabular}

Table 19. The financial comparison between the individual subsystems and the composited system $(1 \mathrm{RMB} \approx 0.16$ U.S. Dollar).

\begin{tabular}{ccc}
\hline Item & IRR (\%) & $\begin{array}{c}\text { Payback } \\
\text { Period (Year) }\end{array}$ \\
\hline The 1200 MW thermal-coal-fired power plants & 18.02 & 6.47 \\
The $2 \times 400$ MW wind farms & 13.51 & 8.81 \\
The $2 \times$ 350 MW low-grade-coal-fired power plants & 12.11 & 9.2 \\
The electrolytic plant of 430 kTon annual production & 35.32 & 3.78 \\
The electrolytic plant of 350 kTon annual production & 5.68 & 18.6 \\
The Composite Isolated Power System & $\mathbf{2 7 . 1 7}$ & $\mathbf{5 . 4 6}$ \\
\hline
\end{tabular}

The risk of the investment is analyzed according to a sensitivity computation. From the analysis results in Table 20, the investment return is more sensitive to the aluminum price than the investment amount and the break-even point is $14,272 \mathrm{RMB} /$ Ton. The investment assumes a low risk considering the average price of aluminum from January 2010 to October 2011 was $16,250 \mathrm{RMB} / \mathrm{Ton}$ [35] and the investors are expected to remain bullish on the aluminum market with China's rapid development.

Table 20. The sensitivity analysis on the investment risk (1 RMB $\approx 0.16$ U.S. Dollar).

\begin{tabular}{cccc}
\hline Uncertainty Factor & Variation (\%) & IRR (\%) & Sensitivity \\
\hline Reference case & 0 & 27.17 & - \\
Aluminum price & -10 & 5.66 & 7.92 \\
Aluminum price & 10 & 59.41 & 11.87 \\
Investment Amount & -10 & 36.53 & -3.44 \\
Investment Amount & 10 & 20.29 & -2.53 \\
\hline
\end{tabular}

\section{Conclusions}

This paper presents a wind-coal hybrid system for aluminum production, the wind/load penetration level of which is designed as high as $47 \%$. With such a high penetration level, this paper discusses the technical and economic issues of the isolated system. From the technical aspect, the power balance conditions of this system are studied for three different scenarios. The proposed hybrid system is demonstrated to be capable of satisfying the load demand from the electrolysis plant in the scenarios of the highest average output, the lowest average output or the highest ramping rate wind power. Therefore, the isolated system is appropriately designed to accommodate the stochastic wind power fluctuations. From the economic aspect, this paper compares the profitability of six individual 
sub-systems with that of the composite isolated system. Since low-grade coal and wind are produced and consumed locally, the proposed hybrid system significantly improves the profitability of the investment by maximizing the utilization of local resources and then avoiding "selling low-buying high" from the state grid. This is demonstrated by the economic comparison of the composite system with any of the individual systems. The investment in the hybrid system is hence proved as valuable and low-risk considering the state of the aluminum market.

\section{Acknowledgement}

This work was supported by the National High-Technology Research and Development Program (“863” Program) of China (2012AA050218) and by the Chinese National Natural Science Funds (51207077).

\section{References}

1. Zhang, S.; Li, X. Large scale wind power integration in China. Analysis from a policy perspective. Renew. Sustain. Energy Rev. 2012, 16, 1110-1115.

2. Detlefsen, N.K.; Sørensen, P.E.; Eriksen, P.B. Managing Critical Weather Conditions in a LargeScale Wind Based European Power System-The Twenties Project. In Proceedings of 2011 IEEE Power \& Energy Society General Meeting, Detroit, MI, USA, July 2011.

3. Langniss, O. Incentives for grid-friendly wind power plants-examples from Spain and Germany. Presented at the Renewable Energy Grid Integration Workshop, Beijing, China, December 2010. Available online: http:/www.efchina.org/csepupfiles/report/201012172020131.9655712788463.pdf/ Incentives\%20for\%20GridFriendly\%20Wind\%20Power\%20Plants_Ole.pdf (accessed on 24 September 2012).

4. Fernández, R.D.; Mantz, R.J.; Battaiotto, P.E. Potential contribution of wind farms to damp oscillations in weak grids with high wind penetration. Renew. Sustain. Energy Rev. 2008, 12, 1692-1711.

5. Kocatepe, C.; İnan, A.; Arıkan, O.; Yumurtaci, R.; Kekezoğlu, B.; Baysal, M.; Bozkurt, A.; Akkaya, Y. Power quality assessment of grid-connected wind farms considering regulations in turkey. Renew. Sustain. Energy Rev. 2009, 13, 2553-2561.

6. Lin, J.; Sun, Y.Z.; Sørensen, P. Model for assessing grid frequency deviation due to wind power fluctuation base on "time-frequency" transformation. IEEE Trans. Sustain. Energy 2012, 3, 65-73.

7. Lin, J.; Sun, Y.Z.; Cheng, L.; Gao, W.Z. Assessment of the power reduction of wind farms under extreme wind condition by a high resolution simulation model. Appl. Energy 2012, 96, 21-32.

8. Zhen, Y.Z.; Ji, H.; Jian, Z. Performance of wind power industry development in China: A diamond model study. Renew. Energy 2009, 34, 2883-2891.

9. Zhang, D.; Zhang, X.; He, J.; Chai, Q. Offshore wind energy development in China: Current status and future perspective. Renew. Sustain. Energy Rev. 2011, 15, 4673-4684.

10. Kaundiny, D.; Balachandra, P.; Ravindranath, N.H. Grid-connected versus stand-alone energy systems for decentralized power-A review of literature. Renew. Sustain. Energy Rev. 2009, 13, 2041-2050. 
11. Luo, C.; Ooi, B.T. Frequency deviation of thermal power plants due to wind farms. IEEE Trans. Energy Convers. 2006, 21, 709-716.

12. Banakar, H.; Luo, C.; Ooi, B.T. Impacts of wind power minute-to-minute variations on power system operation. IEEE Trans. Power Syst. 2008, 23, 150-160.

13. Erdinc, M.U. Optimum design of hybrid renewable energy systems: Overview of different approaches. Renew. Sustain. Energy Rev. 2012, 16, 1412-1425.

14. Ribeiro, L.A.S.; Osvaldo, R.S.; Lima, S.L.; Matos, J.G. Isolated Micro-Grids with renewable hybrid generation: The case of Lençóis island. IEEE Trans. Sustain. Energy 2011, 2, 1-11.

15. Marrero, G.A.; Ramo, F.J. Electricity generation cost in isolated system: The complementarities of natural gas and renewables in the Canary Islands. Renew. Sustain. Energy Rev. 2010, 14, 2808-2818.

16. Ngan, M.S.; Tan, C.W. Assessment of economic viability for PV/wind/diesel hybrid energy system in southern Peninsular Malaysia. Renew. Sustain. Energy Rev. 2012, 16, 634-647.

17. Rehman, S.; Alam, M.M.; Meyer, J.P.; Al-Hadhrami, L.M. Feasibility study of a wind and diesel hybrid power system for a village. Renew. Energy 2012, 38, 258-268.

18. Rehman, S.; El-Aminb, I.M.; Ahmad, F.; Shaahid, S.M.; Al-Shehri, A.M.; Bakhashwain, J.M.; Shash, A. Feasibility study of hybrid retrofits to an isolated off-grid diesel power plant. Renew. Sustain. Energy Rev. 2007, 11, 635-653.

19. Andrade, C.S.; Ros, L.P.; Silv, N.F. Generation of electric energy in isolated rural communities in the Amazon Regional proposal for the autonomy and sustainability of the local populations. Renew. Sustain. Energy Rev. 2011, 15, 493-503.

20. China's electricity consumption up in July. China Daily, 14 August 2010. Available online: http://www.chinadaily.com.cn/china/2010-08/14/content_11154130.htm (accessed on 24 September 2012).

21. Risø National Renewable Energy Laboratory. The Intelligent Energy System Infrastructure for the Future; Technical Report Risø-R-1695 (EN); Risø National Renewable Energy Laboratory: Roskilde, Denmark, September 2009. Available online: http://130.226.56.153/rispubl/reports/ ris-r-1695_uk_summ.pdf (accessed on 24 September 2012).

22. Ma, H.; Oxley, L.; Gibson, J. China's energy situation in the new millennium. Renew. Sustain. Energy Rev. 2009, 13, 1781-1799.

23. Wikipedia. China Power Investment Corporation. Available online: http://en.wikipedia.org/wiki/ China_Power_Investment_Corporation (accessed on 24 September 2012).

24. National Development and Reform Commission. The Notice on the Tariff Concession Cancellation of the Aluminum High-Energy-Consuming Industries; National Development and Reform Commission: Beijing, China, 2007. Available online: http://www.sdpc.gov.cn/zcfb/ zcfbtz/2007tongzhi/t20080222_193192.htm (accessed on 24 September 2012).

25. British Petroleum, BP. The Cost of Generating Electricity: A Study Carried out by BP Power for the Royal Academy of Engineering; The Royal Academy of Engineering: London, UK, 2004. Available online: http://www.raeng.org.uk/news/publications/list/reports/Cost_of_Generating Electricity.pdf (accessed on 24 September 2012).

26. Wikipedia. Inner Mongolian. Available online: http://en.wikipedia.org/wiki/Inner_Mongolia (accessed on 24 September 2012). 
27. CPI Energy Group Meng-Dong Group. Meng-Dong Group Introduction. Available online: http://www.zdhm.com.cn/recruitmentContent-47.shtml (accessed on 24 September 2012).

28. Men, C. Analysis and forecast of Aluminum market. Light Medal. 2003, 11, 3-7.

29. Chinese Standard Bureau. The Wind Resource Assessment Method of Wind Farms; GB/T18710-2002; General Administration of Quality Supervision, Inspection and Quarantine: Beijing, China, 2002.

30. Hansen, A.D.; Sørensen, P.; Iov, F.; Blaabjerg, F. Centralised power control of wind farm with doubly fed induction generators. Renew. Energy 2006, 31, 935-951.

31. WAsP. User Manual. Available online: http://www.wasp.dk/?sc_lang=en (accessed on 24 September 2012).

32. Wikipedia. Internal Rate of Return. Available online: http://en.wikipedia.org/wiki/Internal_rate_ of_return (accessed on 24 September 2012).

33. Bank of China. Deposit Interest Rate. Available online: http://www.boc.cn/finadata/lilv/fd31/ 201107/t20110706_1444098.html (accessed on 24 September 2012).

34. National Bureau of Statistics of China. CPI Indicator. Available online: http://www.stats.gov.cn/ was40/gjtjj_detail.jsp?searchword=5.4\%25\&channelid=6697\&record=1 (accessed on 24 September 2012).

35. Global Metal Network. Aluminum Price. Available online: http://www.ometal.com/historydata/ view.asp? $\mathrm{m}=5 \&$ tmp $=200 \& \mathrm{t}=201 \&$ syear $=2010 \&$ smonth $=01 \&$ eyear $=2011 \&$ emonth $=10$ (accessed on 24 September 2012).

(C) 2012 by the authors; licensee MDPI, Basel, Switzerland. This article is an open access article distributed under the terms and conditions of the Creative Commons Attribution license (http://creativecommons.org/licenses/by/3.0/). 